\title{
Susceptibility to Clotrimazole of Candida spp. Isolated from the Genitourinary System-A Single Center Study
}

\author{
Magdalena Frej-Mądrzak ${ }^{1, *} \mathbb{0}$, Sabina Golec ${ }^{2}$, Katarzyna Włodarczyk ${ }^{2}$, Irena Choroszy-Król ${ }^{1}$ \\ and Urszula Nawrot ${ }^{2}$ (D) \\ 1 Department of Basic Sciences, Faculty of Health Sciences, Wroclaw Medical University, \\ 50-367 Wroclaw, Poland; irena.choroszy-krol@umed.wroc.pl \\ 2 Department of Pharmaceutical Microbiology and Parasitology, Faculty of Pharmacy, \\ Wroclaw Medical University, 50-367 Wroclaw, Poland; sab.golec@gmail.com (S.G.); \\ katarzyna.wlodarczyk@umed.wroc.pl (K.W.); urszula.nawrot@umed.wroc.pl (U.N.) \\ * Correspondence: magdalena.frej-madrzak@umed.wroc.pl; Tel.: +48-71-784-00-13-06
}

Citation: Frej-Mądrzak, M.; Golec, S.; Włodarczyk, K.; Choroszy-Król, I.;

Nawrot, U. Susceptibility to

Clotrimazole of Candida spp. Isolated from the Genitourinary System-A Single Center Study. Pathogens 2021, 10, 1142. https://doi.org/10.3390/ pathogens10091142

Academic Editor: Lawrence S. Young

Received: 20 July 2021

Accepted: 1 September 2021

Published: 4 September 2021

Publisher's Note: MDPI stays neutral with regard to jurisdictional claims in published maps and institutional affiliations.

Copyright: (C) 2021 by the authors Licensee MDPI, Basel, Switzerland. This article is an open access article distributed under the terms and conditions of the Creative Commons Attribution (CC BY) license (https:// creativecommons.org/licenses/by/ $4.0 /)$.

\begin{abstract}
The aim of this study was to determine the susceptibility to clotrimazole of 125 isolates of Candida spp. originated from the genitourinary system of hospitalized patients as well as outpatients, tested in the mycological laboratory of Wroclaw Medical University in the years 1999-2018. The minimal inhibitory concentrations of clotrimazole and fluconazole were determined with the use of the microdilution method according to EUCAST, and the MFC was determined by subsequent subculture on Sabouraud agar. For the tested population of Candida yeasts, the MIC values of clotrimazole ranged from 0.008 to $8 \mathrm{mg} / \mathrm{L}$, and MIC90 was $1 \mathrm{mg} / \mathrm{L}$, whereas MIC50 was $0.008 \mathrm{mg} / \mathrm{L}$. The minimal fungicidal concentration ranged between 1 and $>8 \mathrm{mg} / \mathrm{L}$. The great majority of the isolates $(88 \% ; 110 / 125)$ displayed MIC $<1 \mathrm{mg} / \mathrm{L}$ and were classified as WT (wild-type), whereas MIC $\geq 1 \mathrm{mg} / \mathrm{L}$ was determined for 2/61 (3.2\%) isolates of C. albicans, $9 / 38$ (23.6\%) of C. glabrata, $1 / 2$ of C. tropicalis, and 3/3 of C. guilliermondii. Six isolates (four of C. glabrata and two of C. albicans), defined as non-WT for clotrimazole, were classified as resistant to fluconazole, according to CBP from EUCAST. The isolates with elevated MIC to clotrimazole originated mostly from patients of the pediatric hematology unit, and their proportion in this population amounted to $17.8 \%$ (13 out of 73 isolates). In contrast, among strains from ambulatory patients, the highest observed MIC value was $1 \mathrm{mg} / \mathrm{L}$ ( 1 out of 37 isolates; $2.7 \%$ ). The data obtained correlate well with those of most published studies on the in vitro susceptibility of Candida spp. to clotrimazole, which is usually very high. However, the existence of reports regarding the growing prevalence of resistant isolates has also to be noted. These results support the need for routinely checking the susceptibility of Candida clinical isolates to this imidazole derivative.
\end{abstract}

Keywords: Candida; drug susceptibility; clotrimazole; vulvovaginal

\section{Introduction}

Candida spp. are opportunistic pathogens and an element of the natural microbiota of the human skin and the mucosa of the gastrointestinal and genitourinary systems. At the same time, they are one of the most frequently isolated fungal pathogens involved in superficial as well as deep-seated mycoses. Candidal infections are frequently localized in the mucous membranes of the genitourinary system, and infections occur both in women and men; however, vulvovaginal mycoses are more common. The main pathogen of vulvovaginal candidiasis (VVC) is Candida albicans, which is responsible for up to $85 \%$ of cases of this disease. This condition often arises in patients using hormonal contraceptives, antibiotic therapies, vaginal irrigations, or other procedures leading to disturbance of the microbiota of the vagina and vulva. About $15 \%$ of women with VVC develop a recurrent form of the disease (rVVC), which has been defined as manifesting in at least three (or four) episodes per year [1-3]. 
In addition to C. albicans, other species of this genus (so-called Candida non-albicans), most commonly Candida glabrata, can cause episodic and recurrent VVC. Candida nonalbicans dominate especially in immunosuppressed people, including those with congenital immunodeficiency who, due to the risk of infections, often receive antifungal prophylaxis. In such patients, chronic mucocutaneous candidiasis may be encountered, where the urogenital system may be one of the locations of multifocal mycosis. Candidiasis of the mucous membranes is therefore a clinical problem on a global scale, and due to its high frequency, it also represents an important economic issue. Azoles and polyenes are primarily used in antifungal therapy, but the clinical effectiveness of the therapy is not always satisfactory, as evidenced by reinfections and chronic infections. Clotrimazole is one of the topical drugs most commonly used for candidiasis, although its uncontrolled and/or incorrect use, e.g., prolonged or repeated short-term drug exposure, may contribute to the selection of resistant strains. Whilst there is also a risk of cross-resistance to other azole preparations, currently, there are insufficient clinical data on the development of resistance of the genus Candida to clotrimazole, and susceptibility to this drug is not routinely tested. The aim of this study was to determine the susceptibility to clotrimazole of a collection of 125 isolates of Candida spp. originated from the genitourinary system of hospitalized as well as outpatients, tested in the mycological laboratory of Wroclaw Medical University in the years 1999-2018. The results obtained were compared with data from the literature in terms of the assessment of Candida susceptibility to clotrimazole, the methods used, and the interpretative criteria.

\section{Results}

\section{Susceptibility to Clotrimazole and Fluconazole}

Detailed results of the minimal inhibitory concentration of clotrimazole obtained for each of the 125 tested isolates as well as the MIC of fluconazole determined for 15 isolates are presented in Table S1 (Supplementary). The quantitative distribution of clotrimazole MIC values for particular species is shown in Table 1 and Figure 1.

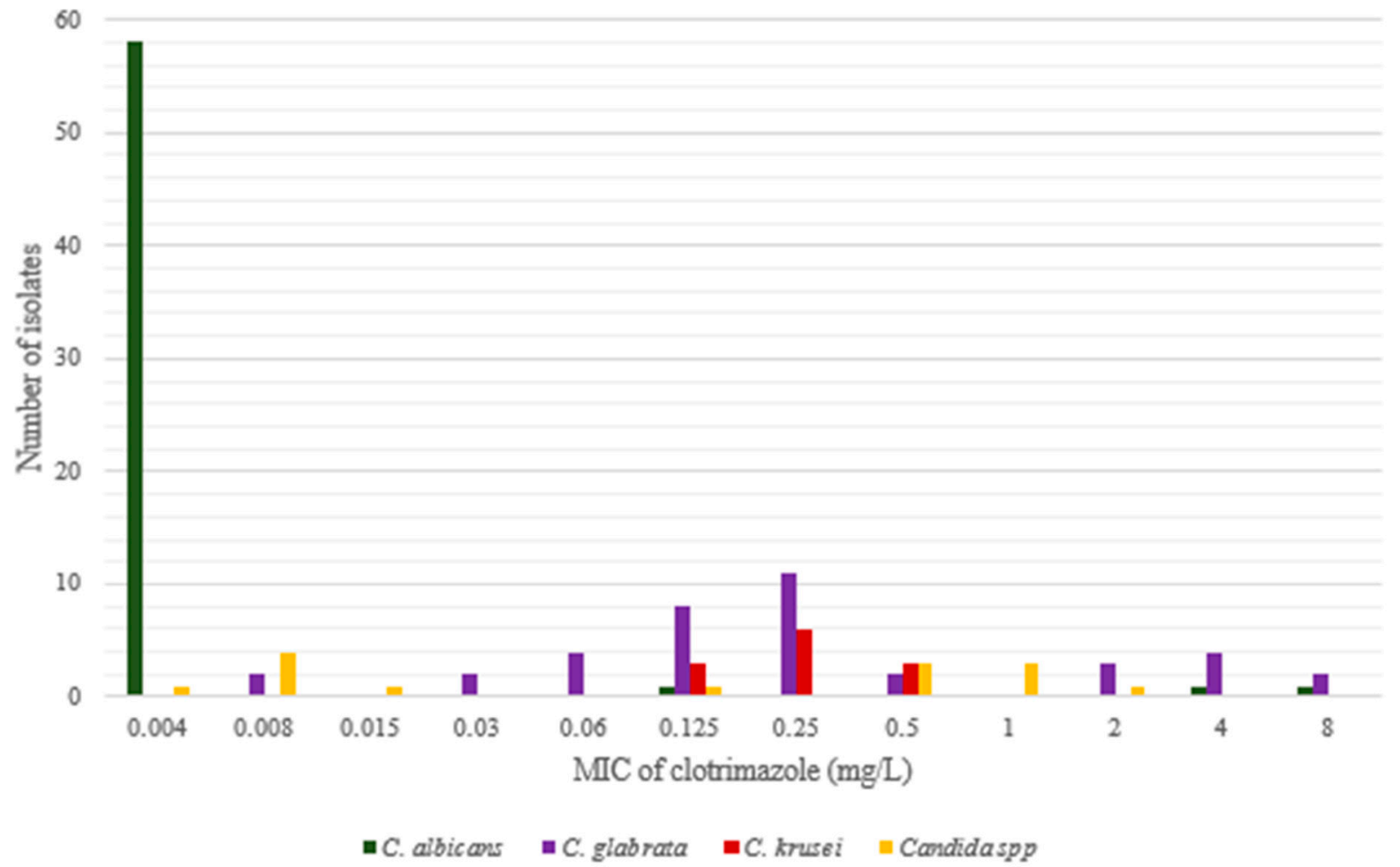

Figure 1. Clotrimazole MIC values for yeasts tested in this study. 
The study indicated that most of C. albicans isolates (58/61,95.08\%) exhibited clotrimazole MICs below $0.008 \mathrm{mg} / \mathrm{L}$; MIC for one isolate was $0.125 \mathrm{mg} / \mathrm{L}$, and that for two other isolates was 4 and $8 \mathrm{mg} / \mathrm{L}$. The last-mentioned isolates also showed elevated MIC to fluconazole and, according to EUCAST breakpoints [4], were classified as susceptible, increased exposure (one isolate), or resistant (two isolates) to this drug (Tables 2 and 3).

Table 1. MIC values of clotrimazole in the tested population of Candida species and comparison with results published by other authors with the use of the CLSI method.

\begin{tabular}{|c|c|c|c|c|c|c|c|c|c|c|c|c|c|c|}
\hline \multirow{2}{*}{$\begin{array}{l}\text { Species } \\
\text { (Number of Isolates) }\end{array}$} & \multicolumn{12}{|c|}{ Number of Isolates at MIC [mg/L] } & \multirow{2}{*}{ MIC50 } & \multirow{2}{*}{ MIC90 } \\
\hline & $<0.008$ & 0.008 & 0.015 & 0.03 & 0.06 & 0.125 & 0.25 & 0.5 & 1 & 2 & 4 & 8 & & \\
\hline C. albicans (61) & 58 & & & & & 1 & & & & & 1 & 1 & $<0.008$ & $<0.008$ \\
\hline $\begin{array}{l}\text { C. albicans (420); } \\
\text { Richter et al. [5] }\end{array}$ & & 9 & 92 & 252 & 65 & 2 & & & & & & & 0.03 & 0.06 \\
\hline C. glabrata (38) & & 2 & & 2 & 4 & 8 & 11 & 2 & & 3 & 4 & 2 & 0.25 & 4 \\
\hline $\begin{array}{l}\text { C. glabrata (250) } \\
\text { Richter et al. [5], } \\
\text { Costa et al. [6]; }\end{array}$ & & & & 1 & 7 & 15 & 21 & 21 & 53 & 45 & 36 & 21 & & \\
\hline C. krusei (12) & & & & & & 3 & 6 & 3 & & & & & 0.25 & 0.5 \\
\hline $\begin{array}{l}\text { C. krusei (12) } \\
\text { Richter et al. [5] }\end{array}$ & & & & & & 2 & 5 & 4 & 1 & & & & 0.25 & 0.5 \\
\hline C. inconspicua (3) & & & & & & 1 & & 2 & & & & & & \\
\hline C. guilliermondii (3) & & & & & & & & & 2 & 1 & & & & \\
\hline C. parapsilosis (2) & & 1 & 1 & & & & & & & & & & & \\
\hline C. tropicalis (2) & & 1 & & & & & & & 1 & & & & & \\
\hline C. dubliniensis (1) & 1 & & & & & & & & & & & & & \\
\hline C. Iusitaniae (1) & & 1 & & & & & & & & & & & & \\
\hline C. pararugosa (1) & & & & & & & & 1 & & & & & & \\
\hline C. melibiosica (1) & & 1 & & & & & & & & & & & & \\
\hline non-albicans. (64) & 1 & 6 & 1 & 2 & 4 & 12 & 17 & 8 & 3 & 4 & 4 & 2 & 0.25 & 2 \\
\hline Total (125) & 59 & 6 & 1 & 2 & 4 & 13 & 17 & 8 & 3 & 4 & 5 & 3 & 0.008 & 1 \\
\hline
\end{tabular}

Table 2. Assessment of the susceptibility to fluconazole of selected strains of Candida spp.

\begin{tabular}{ccccc}
\hline \multirow{2}{*}{ No. } & \multirow{2}{*}{$\begin{array}{c}\text { Strain } \\
\text { Number }\end{array}$} & \multirow{2}{*}{ Species } & \multicolumn{2}{c}{ MIC [mg/L] } \\
\cline { 4 - 5 } & 488 & C. albicans & 0.125 & $4(\mathrm{I})$ \\
\hline 1. & 1050 & C. albicans & 4 & $64(\mathrm{R})$ \\
\hline 2. & 1342 & C. albicans & 8 & $>64(\mathrm{R})$ \\
\hline 3. & 239 & C. glabrata & 2 & $4(\mathrm{I})$ \\
\hline 4. & 2445 & C. glabrata & 2 & $2(\mathrm{I})$ \\
\hline 5. & 984 & C. glabrata & 4 & $4(\mathrm{I})$ \\
\hline 6. & 136 & C. glabrata & 4 & $32(\mathrm{R})$ \\
\hline 7. & 2586 & C. glabrata & 4 & $64(\mathrm{R})$ \\
\hline 8. & 2922 & C. glabrata & 4 & $>64(\mathrm{R})$ \\
\hline 9. & 196 & C. glabrata & 8 & $64(\mathrm{R})$ \\
\hline 10. & & & &
\end{tabular}


Table 2. Cont.

\begin{tabular}{ccccc}
\hline \multirow{2}{*}{ No. } & \multirow{2}{*}{$\begin{array}{c}\text { Strain } \\
\text { Number }\end{array}$} & Species & \multicolumn{2}{c}{ MIC [mg/L] } \\
\cline { 4 - 5 } & 772 & C. glabrata & 8 & Clotrimazole \\
\hline 11. & 630 & C. guillermondii & 2 & $4^{*}$ \\
\hline 12. & 678 & C. guillermondii & 1 & $4^{*}$ \\
\hline 13. & 2933 & C. guillermondii & 1 & $4^{*}$ \\
\hline 14. & 2408 & C. tropicalis & 1 & $4(\mathrm{I})$ \\
\hline 15. & &
\end{tabular}

Explanations to Table 2: Interpretation of the susceptibility to fluconazole according to EUCAST Breakpoint tables for the interpretation of MICs for antifungal agents, Version 10.0, valid from 4 February 2020 R, fluconazoleresistant strain I, susceptible, increased exposure to fluconazole * Candida guilliermondii is a species naturally having higher fluconazole MIC values than Candida albicans, and the epidemiological cut-off (ECOFFs) is $16 \mathrm{mg} / \mathrm{L}$ [4].

Table 3. Susceptibility of different Candida species to clotrimazole; data from the literature.

\begin{tabular}{|c|c|c|c|c|c|c|c|c|}
\hline \multirow{2}{*}{ Reference } & \multirow{2}{*}{ Method } & \multirow{2}{*}{ Sample } & \multirow{2}{*}{$\begin{array}{l}\text { Number of } \\
\text { Strains Tested }\end{array}$} & \multicolumn{4}{|c|}{ Clotrimazole MIC mg/L } & \multirow{2}{*}{$\begin{array}{c}\% \text { of } \\
\text { Non-WT }\end{array}$} \\
\hline & & & & Range & GM & MIC50 & MIC90 & \\
\hline \multicolumn{9}{|c|}{ C. albicans } \\
\hline Shi et al., 2020 [7] & $\begin{array}{l}\text { CLSI, } \\
\text { M27-A3 }\end{array}$ & Vaginal & 1272 & $0.015-32$ & 0.05 & - & 0.25 & ND \\
\hline Rhichter et al., 2005 [5] & CLSI, M27A & Vaginal & 420 & $0.008-0.125$ & & 0.03 & 0.06 & 0 \\
\hline Theill et al., 2016 [8] & $\begin{array}{l}\text { CLSI, } \\
\text { M27-A3 }\end{array}$ & Vaginal & 282 & $0.015-0.12$ & 0.02 & & 0.03 & 0 \\
\hline Zhou et al., 2016 [9] & CLSI, M27A & Vaginal & 216 & $0.03-4$ & 0.046 & $<0.03$ & 0.25 & ND \\
\hline Diaz et al., 2016 [10] & $\begin{array}{l}\text { CLSI, } \\
\text { M27-A3 }\end{array}$ & Vaginal & 126 & $0.03-0.5$ & & 0.03 & 0.06 & 0 \\
\hline Choukri et al., 2014 [11] & $\begin{array}{l}\text { CLSI, } \\
\text { M27-A3 }\end{array}$ & Vaginal & 113 & $0.015-4$ & - & 0.03 & 0.06 & ND \\
\hline Pelletier et al., 2000 [12] & CLSI, M27A & $\begin{array}{l}\text { Oral } \\
(\mathrm{HIV+})\end{array}$ & 87 & $<0.06-8$ & - & $<0.06$ & 0.5 & $15(17 \%)$ \\
\hline Hacioglu et al., 2019 [13] & $\begin{array}{l}\text { CLSI, } \\
\text { M27-A3 }\end{array}$ & Vaginal & 84 & $0.01-2$ & - & 0.007 & 0.25 & ND \\
\hline Nelson et al., 2013 [14] & $\begin{array}{l}\text { CLSI, M27 } \\
\text { A2 }\end{array}$ & Vaginal & 60 & $0.03-16$ & - & 0.25 & 16 & $36.7 \%$ \\
\hline Mesquida et al., 2021 [15] & EUCAST & Vaginal & 72 & $0.004-0.25$ & 0.006 & 0.008 & 0.06 & 0 \\
\hline $\begin{array}{l}\text { Rezaei-Matehkolaei et al., } \\
2016 \text { [16] }\end{array}$ & $\begin{array}{l}\text { microdilution } \\
\text { home } \\
\text { method }\end{array}$ & Vaginal & 30 & $0.25-1$ & 0.29 & 0.25 & 0.5 & $5(16.6 \%)$ \\
\hline Kiakojuri et al., 2021 [17] & CLSI & Auricular & 16 & $1-16$ & 2.484 & 1.5 & 16 & ND \\
\hline \multicolumn{9}{|c|}{ C. dubliniensis } \\
\hline Theill et al., 2016 [8] & $\begin{array}{c}\text { CLSI } \\
\text { M27-A3 }\end{array}$ & Vaginal & 4 & $0.015-0.03$ & & & & ND \\
\hline Shi et al., 2020 [7] & $\begin{array}{l}\text { CLSI, } \\
\text { M27-A3 }\end{array}$ & Vaginal & 1 & 0.015 & & & & ND \\
\hline \multicolumn{9}{|c|}{ C. africana } \\
\hline Shi et al., 2020 [7] & $\begin{array}{l}\text { CLSI, } \\
\text { M27-A3 }\end{array}$ & Vaginal & 49 & $0.15-4$ & - & - & 0.06 & ND \\
\hline Farahyar et al., 2020 [18] & CLSI, M27-S & Vaginal & 3 & $0.06-16$ & - & - & & 1 \\
\hline Theill et al., 2016 [8] & $\begin{array}{l}\text { CLSI } \\
\text { M27-A3 }\end{array}$ & Vaginal & 1 & 0.03 & - & - & & ND \\
\hline \multicolumn{9}{|c|}{ C. glabrata } \\
\hline Shi et al., 2020 [7] & $\begin{array}{l}\text { CLSI, } \\
\text { M27-A3 } \\
\text { CLSI, }\end{array}$ & Vaginal & 267 & $0.015-16$ & 0.2 & - & 1 & ND \\
\hline Costa et al., 2016 [6] & $\begin{array}{l}\text { M27-S4 } \\
\text { /EUCAST }\end{array}$ & Varia & 138 & $0.03-8$ & - & 1 & 8 & $89(64 \%)$ \\
\hline Rhichter et al., 2005 [5] & CLSI, M27A & Vaginal & 112 & $0.06-8$ & - & 1 & 4 & ND \\
\hline Choukri et al., 2014 [11] & $\begin{array}{l}\text { CLSI, } \\
\text { M27-A3 }\end{array}$ & Vaginal & 54 & $0.25-8$ & - & 2 & 4 & ND \\
\hline $\begin{array}{l}\text { Lotfalikhani et al., } \\
\text { 2018 [19] }\end{array}$ & CLSI, M27 & $\begin{array}{l}\text { Vaginal, } \\
\text { blood }\end{array}$ & 41 & $0.1-4$ & - & 0.5 & 4 & $15(30 \%)$ \\
\hline
\end{tabular}


Table 3. Cont.

\begin{tabular}{|c|c|c|c|c|c|c|c|c|}
\hline \multirow{2}{*}{ Reference } & \multirow{2}{*}{ Method } & \multirow{2}{*}{ Sample } & \multirow{2}{*}{$\begin{array}{l}\text { Number of } \\
\text { Strains Tested }\end{array}$} & \multicolumn{4}{|c|}{ Clotrimazole MIC mg/L } & \multirow{2}{*}{$\begin{array}{c}\% \text { of } \\
\text { Non-WT }\end{array}$} \\
\hline & & & & Range & GM & MIC50 & MIC90 & \\
\hline Nelson et al., 2013 [14] & $\begin{array}{l}\text { CLSI, M27 } \\
\quad \text { A2 }\end{array}$ & Vaginal & 28 & $0.03-16$ & - & 0.125 & 0.25 & $10.7 \%$ \\
\hline Diaz et al., 2016 [10] & $\begin{array}{l}\text { CLSI, } \\
\text { M27-A3 }\end{array}$ & Vaginal & 16 & $0.03-1$ & & 0.25 & 1 & ND \\
\hline Zhou et al., 2016 [9] & CLSI, M27A & Vaginal & 13 & $0.03-2$ & 0.2466 & 0.25 & 1 & ND \\
\hline Hacioglu et al., 2019 [13] & $\begin{array}{l}\text { CLSI, } \\
\text { M27-A3 }\end{array}$ & Vaginal & 9 & $0.25-2$ & & 0.5 & 2 & ND \\
\hline $\begin{array}{l}\text { Rezaei-Matehkolaei et al., } \\
\qquad 2016 \text { [16] }\end{array}$ & $\begin{array}{l}\text { microdilution } \\
\text { home } \\
\text { method }\end{array}$ & Vaginal & 3 & 0.25 & & 0.06 & 0.125 & 0 \\
\hline \multicolumn{9}{|c|}{ C. nivariensis } \\
\hline Shi et al., 2020 [7] & $\begin{array}{l}\text { CLSI, } \\
\text { M27-A3 }\end{array}$ & Vaginal & 9 & $0.03-0.5$ & & & & 0 \\
\hline \multicolumn{9}{|c|}{ C. bracariensis } \\
\hline Shi et al., 2020 [7] & $\begin{array}{l}\text { CLSI, } \\
\text { M27-A3 }\end{array}$ & Vaginal & 2 & $0.03-0.5$ & & & & 0 \\
\hline \multicolumn{9}{|c|}{ C. krusei } \\
\hline Shi et al., 2020 [7] & $\begin{array}{l}\text { CLSI, } \\
\text { M27-A3 }\end{array}$ & Vaginal & 54 & $0.015-0.5$ & 0.08 & - & 0.5 & $0 \%$ \\
\hline Singh et al., 2002 [20] & CLSI, M27-A & Vaginal & 26 & $0.03-0.5$ & - & 0.125 & 0.25 & $0 \%$ \\
\hline Rhichter et al., 2005 [7] & CLSI, M27A & Vaginal & 12 & $0.125-1$ & - & 0.25 & 0.5 & $1(3.5 \%)$ \\
\hline Choukri et al., 2014 [11] & $\begin{array}{l}\text { CLSI, } \\
\text { M27-A3 }\end{array}$ & Vaginal & 11 & $0.25-0.5$ & & 0.5 & 0.5 & $0 \%$ \\
\hline Nelson et al., 2013 [14] & $\begin{array}{l}\text { CLSI, } \\
\text { M27-A2 }\end{array}$ & Vaginal & 2 & $1-4$ & & & & $2(100 \%)$ \\
\hline Hacioglu et al., 2019 [13] & $\begin{array}{c}\text { CLSI, } \\
\text { M27-A3 }\end{array}$ & Vaginal & 1 & 0.5 & & & & $0 \%$ \\
\hline \multicolumn{9}{|c|}{ C. parapsilosis } \\
\hline Shi et al., 2020 [6] & $\begin{array}{l}\text { CLSI, } \\
\text { M27-A3 }\end{array}$ & Vaginal & 76 & $0.015-1$ & 0.04 & - & 0.06 & ND \\
\hline Rhichter et al., 2005 [7] & CLSI, M27A & Vaginal & 30 & $0.03-0.5$ & - & 0.06 & 0.25 & $0 \%$ \\
\hline Choukri et al., 2014 [11] & $\begin{array}{l}\text { CLSI, } \\
\text { M27-A3 }\end{array}$ & Vaginal & 11 & $0.03-0.5$ & & 0.12 & 0.12 & $0 \%$ \\
\hline Kiakojuri et al., 2021 [17] & CLSI & auricular & 12 & $1->16$ & 3.364 & 2 & 16 & $12(100 \%)$ \\
\hline Diaz et al., 2016 [10] & $\begin{array}{l}\text { CLSI, } \\
\text { M27-A3 }\end{array}$ & Vaginal & 2 & 0.03 & & & & $0 \%$ \\
\hline Nelson et al., 2013 [14] & $\begin{array}{l}\text { CLSI, M27 } \\
\text { A2 }\end{array}$ & Vaginal & 1 & 0.125 & & & & $0 \%$ \\
\hline \multicolumn{9}{|c|}{ C. metapsilosis } \\
\hline Shi et al., 2020 [6] & $\begin{array}{l}\text { CLSI, } \\
\text { M27-A3 }\end{array}$ & Vaginal & 20 & $0.03-0.25$ & 0.04 & - & 0.06 & $0 \%$ \\
\hline \multicolumn{9}{|c|}{ C. orthopsilosis } \\
\hline Kiakojuri et al., 2021 [17] & CLSI & Auricular & 18 & $0.25->16$ & 1.782 & 1 & 16 & \\
\hline Shi et al., 2020 [6] & $\begin{array}{l}\text { CLSI, } \\
\text { M27-A3 }\end{array}$ & Vaginal & 6 & $0.03-1$ & & & 1 & \\
\hline \multicolumn{9}{|c|}{ C. tropicalis } \\
\hline Shi et al., 2020 [6] & $\begin{array}{l}\text { CLSI, } \\
\text { M27-A3 }\end{array}$ & Vaginal & 61 & $0.015-0.25$ & 0.05 & - & 0.05 & 0 \\
\hline Choukri et al., 2014 [11] & $\begin{array}{l}\text { CLSI, } \\
\text { M27-A3 }\end{array}$ & Vaginal & 11 & $0.12-0.25$ & - & 0.12 & 0.25 & 0 \\
\hline Rhichter et al., 2005 [7] & CLSI, M27A & Vaginal & 8 & $0.03-0.25$ & - & & & 0 \\
\hline Nelson et al., 2013 [14] & $\begin{array}{l}\text { CLSI, M27 } \\
\text { A2 }\end{array}$ & Vaginal & 3 & $0.125-2$ & & & & $1(33.3 \%)$ \\
\hline Hacioglu et al., 2019 [13] & $\begin{array}{l}\text { CLSI, } \\
\text { M27-A3 }\end{array}$ & Vaginal & 2 & $0.007-0.015$ & & & & 0 \\
\hline Kiakojuri et al., 2021 [17] & CLSI & Auricular & 1 & 4 & & & & $1(100 \%)$ \\
\hline Diaz et al., 2016 [10] & $\begin{array}{c}\text { CLSI, } \\
\text { M27-A3 }\end{array}$ & Vaginal & 1 & 1 & & & & $1(100 \%)$ \\
\hline
\end{tabular}


Table 3. Cont.

\begin{tabular}{|c|c|c|c|c|c|c|c|c|}
\hline \multirow{2}{*}{ Reference } & \multirow{2}{*}{ Method } & \multirow{2}{*}{ Sample } & \multirow{2}{*}{$\begin{array}{l}\text { Number of } \\
\text { Strains Tested }\end{array}$} & \multicolumn{4}{|c|}{ Clotrimazole MIC mg/L } & \multirow{2}{*}{$\begin{array}{c}\% \text { of } \\
\text { Non-WT }\end{array}$} \\
\hline & & & & Range & GM & MIC50 & MIC90 & \\
\hline \multicolumn{9}{|c|}{ C. kefyr } \\
\hline Hacioglu et al., 2019 [13] & $\begin{array}{c}\text { CLSI, } \\
\text { M27-A3 }\end{array}$ & Vaginal & 2 & $0.007-0.5$ & & & & \\
\hline $\begin{array}{l}\text { Rezaei-Matehkolaei et al., } \\
2016 \text { [16] }\end{array}$ & $\begin{array}{l}\text { microdilution } \\
\text { home } \\
\text { method }\end{array}$ & Vaginal & 1 & 0.25 & & & & \\
\hline \multicolumn{9}{|c|}{ C. auris } \\
\hline Kiakojuri et al., 2021 [17] & CLSI & auricular & 1 & 8 & & & & \\
\hline \multicolumn{9}{|c|}{ C. lusitniae } \\
\hline Rhichter et al., 2005 [7] & CLSI, M27A & Vaginal & 1 & 0.06 & & & & \\
\hline Hacioglu et al., 2019 [13] & $\begin{array}{l}\text { CLSI, } \\
\text { M27-A3 }\end{array}$ & Vaginal & 1 & 0.5 & & & & \\
\hline
\end{tabular}

Abbreviations: ND, no data; non-WT, non-wild-type phenotype.

In the population of $C$. glabrata, most isolates showed clotrimazole MIC between 0.008 and $0.5 \mathrm{mg} / \mathrm{L}$; nevertheless 9 out of $38(23.6 \%)$ isolates displayed MIC above $1 \mathrm{mg} / \mathrm{L}(2-8 \mathrm{mg} / \mathrm{L})$. Five isolates of this subgroup were classified as resistant to fluconazole (Table 2). The clotrimazole MIC values for Candida krusei were subdivided in a narrow range from 0.125 to 0.5 , and those for Candida parapsilosis from 0.015 to 0.03 ; MIC for Candida tropicalis was 0.008 for one strain and $1 \mathrm{mg} / \mathrm{L}$ for the second one. For three isolates of Candida guilliermondii, the MIC of clotrimazole was $1 \mathrm{mg} / \mathrm{L}$ (two strains) and $2 \mathrm{mg} / \mathrm{L}$ (one isolate), whereas the MIC of fluconazole for these isolates was $4 \mathrm{mg} / \mathrm{L}$ (wild-type phenotype according to EUCAST). Among Candida non-albicans, the lowest MIC values were found for Candida dubliniensis $(<0.008 \mathrm{mg} / \mathrm{L})$ and for representatives of Candida lusitaniae and Candida melibiosica $(0.008 \mathrm{mg} / \mathrm{L})$. The clotrimazole MIC50 (the lowest concentration of clotrimazole inducing growth inhibition of $50 \%$ in the tested population of isolates) for the whole population of tested Candida was $0.008 \mathrm{mg} / \mathrm{L}$, while the MIC90 (the lowest concentration of clotrimazole inducing growth inhibition of $90 \%$ in the tested population of isolates) was $1 \mathrm{mg} / \mathrm{L}$. The minimal fungicidal concentration ranged between 1 and $>8 \mathrm{mg} / \mathrm{L}$. The ratio of MFC/MIC ranged from 1 (for one isolate of C. glabrata) to $>500$ for $C$. albicans (Table S1). The clotrimazole MICs for the reference strains were as follows: C. glabrata ATCC 90030, $0.125 \mathrm{mg} / \mathrm{L}$, C. albicans ATCC 90028, $0.008 \mathrm{mg} / \mathrm{L}, \mathrm{C}$. albicans ATCC 10231, $0.03 \mathrm{mg} / \mathrm{L}$, and C. krusei ATCC 6258, $0.125 \mathrm{mg} / \mathrm{L}$.

\section{Discussion}

Clotrimazole, an imidazole derivative introduced to the market about 45 years ago, is still one of the most commonly used topical antimycotics in the treatment of mucocutaneous candidiasis. A long-term treatment in cases of chronic or recurrent infections, e.g., rVVC, as well as an improper dosage facilitated by the universal access to this medicine (usually available on medical prescription), pose a risk of the development of strains with acquired resistance to azoles. Surprisingly, cases of such resistance are reported relatively seldom, which may also be due to the fact that, usually, susceptibility to this drug is not checked by routine microbiological testing. For this reason, there is no comprehensive knowledge concerning the presence of clotrimazole resistance and the risk of its emergence during treatment [21].

In this study, we estimated the susceptibility to clotrimazole of 125 strains of Candida spp. isolated from the mucous membranes of the genitourinary system. The isolates represented a heterogeneous group in terms of origin. The samples were isolated from adults (54/125 isolates), from symptomatic infections, while the controls (73 isolates) were obtained during screening from usually asymptomatic children hospitalized in the hematology clinic. Overall, in the studied population of strains, $48.8 \%(61 / 125)$ of the isolates were $C$. albicans, while the next most frequent species were C. glabrata $30.4 \%(38 / 125)$ 
and C. krusei $9.6 \%(12 / 125)$. All other species of Candida accounted for $11 \%$. The proportion of Candida spp. (C. non-albicans) among the isolates from the children was higher $(48 / 73$; $65 \%$ ) than among the isolates from the adults $(27 \%)$, which may be related to the use of antifungal prophylaxis effective against C. albicans (e.g., fluconazole), which is a standard procedure in hematology. The analysis of the susceptibility to clotrimazole indicated that $88 \%$ (110/125) of Candida spp. isolates showed MIC values lower than $1 \mathrm{mg} / \mathrm{L}$. All but two isolates with a MIC $\geq 1 \mathrm{mg} / \mathrm{L}$ originated from the patients of the pediatric hematology unit; thus, their proportion in this population amounted to $17.8 \%$ (13 out of 73 isolates). In contrast, among strains from ambulatory patients, the highest observed MIC value was $1 \mathrm{mg} / \mathrm{L}$ (1 out of 37 isolates; $2.7 \%$ ). The MIC of $0.5 \mathrm{mg} / \mathrm{L}$ (value used as a cut-off in some studies) was determined for eight isolates of Candida non-albicans, and the overall proportion of isolates with a MIC $\geq 0.5 \mathrm{mg} / \mathrm{L}$ was $18.4 \%(23 / 125)$.

The frequency of clotrimazole resistance reported by other authors differs from study to study and could be related not only to the epidemiological resources but also to the method of susceptibility testing. In the present study, we applied the reference microdilution method, recommended by EUCAST. A great difficulty related to this method is the interpretation of the MIC results, which is based on clinical breakpoint values, the determination of which requires not only extensive microbiological examination but also clinical analysis. Currently, neither EUCAST nor CLSI have published data regarding both clinical and epidemiological MIC breakpoints for clotrimazole. It is well known that the susceptibility to antimicrobials and MIC values are species-specific. C. albicans and closely related species (C. africana, C. dubliniensis) are regarded as very sensitive to azoles, including clotrimazole. This rule was confirmed by several studies (including this article), in which MIC90 for these species ranged between 0.03 and $0.5 \mathrm{mg} / \mathrm{L}$ (Table 3) [6-13,15].

Pelletier et al., in their study performed 20 years ago on $87 \mathrm{C}$. albicans isolates, suggested a MIC $\geq 0.5 \mathrm{mg} / \mathrm{L}$ as a tentative breakpoint indicating resistance [12]. In the above-mentioned study, $17 \%(15 / 87)$ of the tested isolates showed a MIC $\geq 0.5 \mathrm{mg} / \mathrm{L}$ and were regarded as resistant. The authors found that a MIC of clotrimazole $\geq 0.5 \mathrm{mg} / \mathrm{L}$ correlated with a significant risk of cross-resistance to other azoles such as fluconazole and itraconazole. A few years later, Richter et al. [5] published a study in which they examined the susceptibility to clotrimazole and other azoles of almost 600 clinical yeast isolates obtained from the genital tract and adopted a MIC of $1 \mathrm{mg} / \mathrm{L}$ as the cut-off for resistance to clotrimazole for all Candida species included in the study. However, none of the 420 strains of $C$. albicans tested by Richter et al. showed a MIC higher than $0.125 \mathrm{mg} / \mathrm{L}$. By contrast, in the study of Nelson et al. [14], the percentage of clotrimazole-resistant C. albicans was $36.6 \%$.

A very interesting study was described by Marchaim et al. [22], who analyzed cases of recurrent vaginitis due to fluconazole-resistant Candida albicans. Patients were exposed to a long-term treatment with fluconazole, and most of them received a low dose of fluconazole weekly during a 12 month period before the isolation of a resistant strain. The isolates with an elevated MIC of clotrimazole $(\geq 0.5 \mathrm{mg} / \mathrm{L})$ were resistant to fluconazole, with a MIC of 4-128 mg/L. Similarly, in our study, both detected isolates of Candida albicans with clotrimazole MIC > $0.5 \mathrm{mg} / \mathrm{L}$ were cross-resistant to fluconazole. As mentioned above, resistant strains were obtained from children from the hematological department, who, similarly to patients with rVVC described by Marchaim et al., received antifungal therapy. Cross resistance between clotrimazole and other azoles was described by other authors, e.g., Khadka et al. [23], who used a disc diffusion method recommended by the Clinical and Laboratory Standards Institute (CLSI, M44-A). Among 56 C. albicans isolates, 8 (14.3\%) were classified as SDD (susceptible, dose-dependently), and 4 (7.2\%) as resistant to clotrimazole. The strains reported to be resistant to clotrimazole showed cross resistance to other azoles, including fluconazole [23].

C. glabrata isolates with known lower susceptibility to azoles (especially, fluconazole) represent the second most frequent cause of candidosis of the genitourinary tract. The isolates of C. glabrata included in this study showed a wide range of MIC values for 
clotrimazole (between $0.015 \mathrm{mg} / \mathrm{L}$ and $8 \mathrm{mg} / \mathrm{L}$ ). Most isolates (29/38; 76.3\%) displayed a $\mathrm{MIC} \leq 0.5 \mathrm{mg} / \mathrm{L}$, whereas $23 \%$ (9/38) of them showed MIC $>0.5 \mathrm{mg} / \mathrm{L}$ and were regarded as non-wild-type (non-WT). The MIC50 of the entire pool of the tested C. glabrata strains was $0.25 \mathrm{mg} / \mathrm{L}$, while the MIC90 was $4 \mathrm{mg} / \mathrm{L}$. The values of MIC90 of C. glabrata obtained by many other authors ranged between 1 and $4 \mathrm{mg} / \mathrm{L}$ (Table 3) [5,7,9-11,13,14,16,19]. An exception are the results obtained by Costa et al. [6], who analyzed C. glabrata isolated from different clinical samples of hospitalized patients, previously exposed to antifungal therapy. The authors found $64 \%$ of the tested isolates resistant to clotrimazole (MIC90 equal to $8 \mathrm{mg} / \mathrm{L}$ ) and, simultaneously, 15\% of them resistant to fluconazole (MIC $\geq 32 \mathrm{mg} / \mathrm{L}$ ). Similarly, in the present study, five out of nine C. glabrata isolates with an elevated MIC of clotrimazole proved to be resistant to fluconazole, with an MIC $\geq 32 \mathrm{mg} / \mathrm{L}$ (Table 2). This indicates that these isolates harbor a resistance mechanism resulting in a simultaneous loss of susceptibility to both clotrimazole and fluconazole. The strains with pan-azole resistance could be selected during oral therapy with fluconazole as well as during topical treatment with over-the-counter azoles, e.g., clotrimazole. Such thesis supports the study by Cross et al., who observed the spontaneous development of resistant C. glabrata mutants under the selective pressure of clotrimazole [24]. Costa et al. [6] demonstrated that the resistance of C. glabrata to clotrimazole correlated with increased expression of genes encoding DHA membrane transporters (Drug: H + Antiporters): CgAqr1, CgQdr2, CgTpo11 , and CgTpo3, a type of efflux pump related to the ABC pump family (ATP Binding Cassette). This was evidenced by a decrease in resistance of the tested strains to clotrimazole after deletion of the gene coding for $\mathrm{CgTpo3,} \mathrm{which} \mathrm{resulted} \mathrm{in} \mathrm{increased} \mathrm{accumulation} \mathrm{of}$ this drug in fungal cells. The results of this study suggest a role of the CgTpo3 transporter in the development of the resistance mechanism to clotrimazole and other azole drugs (including fluconazole) [6].

C. krusei, a relatively rare pathogen of the genital tract, is regarded as being naturally resistant to fluconazole and frequently less susceptible to other azoles. Isolates of C. krusei tested in the present study showed low MIC values for clotrimazole $(0.125-0.5 \mathrm{mg} / \mathrm{L})$ and belonged to the WT population, despite the fact that $50 \%$ of them were isolated from a population at risk (children from the hematology department). Similar results were obtained in studies by Richter et al. [5] and Singh et al. [20]. They obtained MIC values of clotrimazole that did not exceed $1 \mathrm{mg} / \mathrm{L}$. Singh et al. [20] found clotrimazole to be the most potent azole derivative against $C$. krusei isolated from chronic vulvovaginal candidiasis. However, clotrimazole-resistant isolates of C. krusei were also reported in the literature (Nelson et al. [14]).

The percentage of genitourinary tract infections caused by C. parapsilosis and C. tropicalis is relatively low and oscillates around 6\% [25]. In our study, each of these species was represented by two isolates, one isolate of $C$. tropicalis was non-WT with a MIC of $1 \mathrm{mg} / \mathrm{L}$, and the balance of the isolates were susceptible. The vaginal isolates of C. parapsilosis and C. tropicalis studied by other authors had usually a WT phenotype and displayed a low MIC of clotrimazole [5]. These species, similar to C. albicans, usually showed good susceptibility to triazoles, especially to fluconazole. An extraordinary result was reported recently by Kiakojuri et al., 2021, who tested isolates from patients with otomycosis and found that all of the C. parapsilosis isolates and most of the closely related Candida orthopsilosis ones were resistant to clotrimazole (MIC90 $16 \mathrm{mg} / \mathrm{L}$ ) as well fluconazole (MIC90 $64 \mathrm{mg} / \mathrm{L}$ ) [17].

In the present study, we also tested some of the less frequently encountered Candida species (C. inconspicua, C. Iusitaniae, C. pararugosa, C. melibiosica), and most of them were susceptible to clotrimazole (MIC $<0.5 \mathrm{mg} / \mathrm{L}$ ). The exception was strains of $C$. guilliermondii which showed clotrimazole MIC values of 1 or $2 \mathrm{mg} / \mathrm{L}$ and fluconazole MIC of $4 \mathrm{mg} / \mathrm{L}$ (phenotype WT in relation to fluconazole; ECOFF $16 \mathrm{mg} / \mathrm{L}$ ) [4].

The data regarding the susceptibility of clinical isolates of Candida to clotrimazole, published in this study as well as in the current medical literature, indicated that the proportion of non-susceptible strains is rather low, especially in isolates obtained from the general population. An alarmingly high representation of resistant isolates has been 
reported mostly in high-risk populations exposed to prolonged azole (usually triazole) treatment. Evaluation and comparison of the susceptibility data of particular Candida species are difficult. Although clotrimazole has been used for a long time, a reliable method of interpretation of the MIC data (clinical breakpoints and epidemiological cut-off) has not yet been established. Analysis of published MIC data for C. albicans indicates that the tentative breakpoint proposed by Pelletier et al. [12] could be accepted for this species. On the other hand, the distribution of MIC values for C. glabrata indicates that its ECOFF is higher than that of $C$. albicans and a value of at least $1-2 \mathrm{mg} / \mathrm{L}$ is reasonable. The therapeutic effectiveness of antifungal therapy is not always well correlated with the susceptibility data. It especially concerns a topical treatment, when the distribution of the concentration of the compound may greatly exceed the MIC values, even for strains belonging to the non-WT population. The low water solubility, as well as the increase in the MIC value in an acidic environment $(\mathrm{pH} 4)$ observed for clotrimazole, may be a reason for a lower-than-expected antifungal effect $[26,27]$. This may be connected with the fact that the action of azole derivatives, including clotrimazole, against Candida species is usually fungistatic. The lack of eradication of the microorganism could result in the development of persistent infections or reinfections in the future. Among the factors influencing the efficacy of an antifungal therapy we can list patient-related errors. An improper application of the drug or its irregular use may be a secondary cause of an unsatisfactory clinical response. To improve topical treatments, new drug formulations are under development, e.g., combinations with chitosan [26], intravaginal rings [28], clotrimazole-loaded polymeric micelles with hyaluronic acid [29], and many others.

In order to determine the effectiveness of the clotrimazole therapy as well as to develop reliable diagnostic standards of susceptibility testing, it is necessary to conduct simultaneous clinical and microbiological tests.

\section{Materials and Methods}

\subsection{Strains}

The study was performed on 125 Candida spp. isolates preserved in the laboratory collection of the Department of Pharmaceutical Microbiology and Parasitology of the Wroclaw Medical University. Of these, 14 isolates were incorporated from the collection of the Department of Basic Sciences, Faculty of Health Sciences of the Wroclaw Medical University. The isolates were derived during routine microbiological examinations in the years $1999-2018$ and were preserved frozen at $-71^{\circ} \mathrm{C}$ in TSB medium supplemented with $15 \%$ glycerol. The strains originated from the following clinical materials: vaginal smears (67), swabs from the cervix (19), swabs from under the foreskin (31), and swabs from the skin or wounds (8). Most strains (88) were isolated from hospitalized patients, including those in the adult and pediatric hematology unit (74 strains), intensive care unit (7), gynecology (5), and surgery, (2) and the remaining 37 isolates were from ambulatory patients. The strains tested were identified as follows: Candida albicans (61), Candida glabrata (38), Candida krusei (12), Candida guillermondii (3), Candida inconspicua (3), Candida parapsilosis (2), Candida tropicalis (2), and one each of Candida dubliniensis, Candida lusitaniae, Candida pararugosa, and Candida melibiosica. Details of the origin of the strains are provided in Table S1 (Supplement). Apart from the clinical isolates, the following reference strains from the American Type Culture Collection were investigated: Candida albicans ATCC 90028, Candida albicans ATCC 10231, and Candida glabrata ATCC 90030.

\subsection{Culture and Re-Identification of the Strains}

For cultivation, the strains stored at $-70^{\circ} \mathrm{C}$ were thawed and streaked on Sabouraud Dextrose Chloramphenicol Agar (BioMaxima, Poland) medium, then incubated at $37^{\circ} \mathrm{C}$ for 24-48 h. Colony morphology was assessed for culture purity, and single colonies were screened with chromogenic CHROMagar ${ }^{\mathrm{TM}}$ Candida medium (BioMaxima, Poland), which enables the differentiation of C. albicans, C. krusei, C. tropicalis, and Candida spp., as well as with Chromogenic Candida Plus Lab-Agar ${ }^{\mathrm{TM}}$, (BioMaxima, Poland), which 
additionally allowed the detection of the species Candida auris. The isolates classified as Candida spp. were subsequently investigated on the basis of their morphology in microculture on rice agar medium as well as of their biochemical profile with BD Phoenix ${ }^{\mathrm{TM}}$ Yeast ID tests and the Phoenix ${ }^{\mathrm{TM}} 100$ (Becton Dickinson) system, in accordance with the manufacturer's instructions.

\subsection{Determination of Susceptibility to Antifungals/Clotrimazole}

Susceptibility to clotrimazole (Hasco Lek, Poland) and fluconazole (Sigma-Aldrich) was tested with the use of the microdilution method according to EUCAST E.Def 7.3.2 [30]. Briefly, the investigation was carried out in liquid RPMI 1640 medium supplemented with $2 \%$ glucose and buffered with MOPS (3-(N-morpholino) propanesulfonic acid) (Sigma Aldrich); $96 \%$ ethanol was used to dissolve clotrimazole, and sterile distilled water to dissolve fluconazole.

A stock solution of clotrimazole of $1600 \mathrm{mg} / \mathrm{L}$ in $96 \%$ ethanol was used to prepare a series of 2-fold ethanol solutions at concentrations ranging from $1.562 \mathrm{mg} / \mathrm{L}$ to $800 \mathrm{mg} / \mathrm{L}$. Subsequently, they were diluted again in double-strength RPMI $16,402 \times$, to obtain clotrimazole concentrations ranging from $0.0156 \mathrm{mg} / \mathrm{L}$ to $16 \mathrm{mg} / \mathrm{L}$. The prepared solutions were dispensed in a volume of $50 \mu \mathrm{L}$ into the appropriate wells of 96-well microplates. In the case of fluconazole, the drug concentrations in the microtiter plates ranged from $0.25 \mathrm{mg} / \mathrm{L}$ to $128 \mathrm{mg} / \mathrm{L}$. The microplates were preserved frozen at $-76^{\circ} \mathrm{C}$ until used. Before drug susceptibility testing, the investigated strains were cultured at $37^{\circ} \mathrm{C}$ for $24 \mathrm{~h}$ on Sabouraud dextrose agar medium. Fungal cells were suspended in distilled water to obtain a density of $0.5 \mathrm{McF}$ arland $\left(1-5 \times 10^{6} \mathrm{CFU} / \mathrm{mL}\right)$ and thereafter diluted 1 in 10 to obtain $1-5 \times 10^{5} \mathrm{CFU} / \mathrm{mL}$. The prepared inoculum of each strain was applied in a volume of $50 \mu \mathrm{L}$ to the wells with antimycotics as well as to growth control (RPMI $16402 \times$ without antimycotics). The final density of the fungal suspension (applied to the microtiter plate) was in the range $0.5-2.5 \times 10^{5} \mathrm{CFU} / \mathrm{mL}$, and the final clotrimazole concentrations were $0.006-8 \mathrm{mg} / \mathrm{L}$, whereas those of fluconazole were $0.125-64 \mathrm{mg} / \mathrm{L}$. All inoculation activities were performed under sterile conditions in a laminar-flow cabinet. Inoculated microplates were incubated for $24 \mathrm{~h}$ at $37^{\circ} \mathrm{C}$. The absorbance of the samples in each well was then measured by a Multiscan Go spectrophotometer at a wavelength of $530 \mathrm{~nm}$. The MIC value was determined as the lowest concentration of the antimycotic expressed in $\mathrm{mg} / \mathrm{L}$ at which the absorbance value was at least $50 \%$ lower than that of the control strain in the same medium without the antibiotic. The interpretation of the results was based on the clinical breakpoints published by EUCAST (fluconazole) [17] and the publication of Richter et al. and Pelletier et al. (clotrimazole) [7,12].

\subsection{Determination of MFC, the Minimal Fungicidal Concentration of Clotrimazole}

After microplate incubation and determination of the MIC values for 22 randomly selected strains, the minimum fungicidal concentration (MFC) of clotrimazole was determined. For this purpose, an aliquot of $20 \mu \mathrm{L}$ of the culture medium was taken from a well of the microplate, where no growth (no turbidity) was observed and plated on Sabouraud dextrose agar plates. Subsequently, these media were incubated at $37^{\circ} \mathrm{C}$ for $24-48 \mathrm{~h}$. The lowest concentration at which $\leq 1$ colony growth was observed was considered the MFC.

\section{Conclusions}

Candida albicans was highly sensitive to clotrimazole. Strains with a non-WT phenotype which were detected in only two patients of the oncology department. The MICs of clotrimazole for Candida non-albicans strains were higher than those of for Candida albicans, and the non-WT strains most often belonged to the species Candida glabrata. Strains with the non-WT phenotype with respect to clotrimazole showed different sensitivity to fluconazole (cross resistance to fluconazole and clotrimazole or resistance to clotrimazole only). This suggests the existence of various resistance mechanisms and indicates the need to measure drug susceptibility in diagnostic tests. 
Supplementary Materials: The following are available online at https:/ / www.mdpi.com/article/1 0.3390 / pathogens10091142/s1, Table S1: List of tested strains, their origin, and susceptibility results.

Author Contributions: Conceptualization, U.N. and M.F.-M.; methodology, U.N., S.G., K.W. and M.F.-M.; validation, U.N., S.G., K.W. and M.F.-M.; formal analysis, M.F.-M.; investigation, S.G. and K.W.; resources, U.N., K.W. and M.F.-M.; data curation, U.N., M.F.-M. and S.G.; writing-original draft preparation, S.G., M.F.-M. and U.N.; writing-review and editing, U.N., M.F.-M. and I.C-K.; supervision, U.N. and I.C.-K.; project administration, U.N.; funding acquisition, U.N. and I.C.-K.; All authors have read and agreed to the published version of the manuscript.

Funding: The susceptibility tests included in this article were financially supported by Wrocław Medical University Statutory Funding SUB.D230.21.102.

Institutional Review Board Statement: The strains investigated in his study were obtained in years 1999-2018 during several projects, which were approved by the Wroclaw Medical University Bioethics Committee: No. 487/2005, No. 89/2012.

Informed Consent Statement: Informed consent was obtained from all subjects involved in the study. Data Availability Statement: Data are contained within the article or supplementary material.

Conflicts of Interest: The authors declare no conflict of interest.

\section{References}

1. Yapar, N. Epidemiology and risk factors for invasive candidiasis. Ther. Clin. Risk Manag. 2014, 10, 95-105. [CrossRef]

2. Sardi, J.; Scorzoni, L.; Bernardi, T.; Fusco-Almeida, A.M.; Mendes Giannini, M. Candida species: Current epidemiology, pathogenicity, biofilm formation, natural antifungal products and new therapeutic options. J. Med. Microbiol. 2013, 62, 10-24. [CrossRef]

3. Gonçalves, B.; Ferreira, C.; Alves, C.T.; Henriques, M.; Azeredo, J.; Silva, S. Vulvovaginal candidiasis: Epidemiology, microbiology and risk factors. Crit. Rev. Microbiol. 2016, 42, 905-927. [CrossRef]

4. The European Committee on Antimicrobial Susceptibility Testing. Overview of Antifungal ECOFFs and Clinical Breakpoints for Yeasts, Moulds and Dermatophytes Using the EUCAST E.Def 7.3, E.Def 9.3 and E.Def 11.0 Procedures. Version 2. 2020. Available online: http:/ / www.eucast.org. (accessed on 19 October 2020).

5. Richter, S.S.; Galask, R.P.; Messer, S.A.; Hollis, R.J.; Diekema, D.J.; Pfaller, M.A. Antifungal susceptibilities of Candida species causing vulvovaginitis and epidemiology of recurrent cases. J. Clin. Microbiol. 2005, 43, 2155-2162. [CrossRef]

6. Costa, C.; Ribeiro, J.; Miranda, I.M.; Silva-Dias, A.; Cavalheiro, M.; Costa-de-Oliveira, S.; Rodrigues, A.G.; Teixeira, M.C. Clotrimazole drug resistance in Candida glabrata clinical isolates correlates with increased expression of the drug: $\mathrm{H}(+)$ antiporters CgAqr1, CgTpo1_1, CgTpo3, and CgQdr2. Front. Microbiol. 2016, 7, 526. [CrossRef]

7. Shi, Y.; Zhu, Y.; Fan, S.; Liu, X.; Liang, Y.; Shan, Y. Molecular identification and antifungal susceptibility profile of yeast from vulvovaginal candidiasis. BMC Infect. Dis. 2020, 20, 287. [CrossRef] [PubMed]

8. Theill, L.; Dudiuk, C.; Morano, S.; Gamarra, S.; Nardin, M.E.; Méndez, E.; Garcia-Effron, G. Prevalence and antifungal susceptibility of Candida albicans and its related species Candida dubliniensis and Candida africana isolated from vulvovaginal samples in a hospital of Argentina. Rev. Argent. Microbiol. 2016, 48, 43-49.

9. Zhou, X.; Li, T.; Fan, S.; Zhu, Y.; Liu, X.; Guo, X.; Liang, Y. The efficacy and safety of clotrimazole vaginal tablet vs. oral fluconazole in treating severe vulvovaginal candidiasis. Mycoses 2016, 59, 419-428. [CrossRef] [PubMed]

10. Diaz, M.C.; Camponovo, R.; Araya, I.; Cerda, A.; Santander, M.P.; Carrillo-Muñoz, A.J. Identificación y sensibilidad antifúngica in vitro de Candida spp. de origen vaginal a fluconazol, clotrimazol y nistatina [Identification and in vitro antifungal susceptibility of vaginal Candida spp. isolates to fluconazole, clotrimazole and nystatin]. Rev. Esp. Quimioter. 2016, 29, 151-154.

11. Choukri, F.; Benderdouche, M.; Sednaoui, P. In vitro susceptibility profile of 200 recent clinical isolates of Candida spp. to topical antifungal treatments of vulvovaginal candidiasis, the imidazoles and nystatin agents. J. Mycol. Med. 2014, 24, 303-307. [CrossRef] [PubMed]

12. Pelletier, R.; Peter, J.; Antin, C.; Gonzalez, C.; Wood, L.; Walsh, T.J. Emergence of resistance of Candida albicans to clotrimazole in human immunodeficiency virus-infected children: In vitro and clinical correlations. J. Clin. Microbiol. 2000, 38, 1563-1568. [CrossRef] [PubMed]

13. Hacioglu, M.; Guzel, C.B.; Savage, P.B.; Tan, A. Antifungal susceptibilities, in vitro production of virulence factors and activities of ceragenins against Candida spp. isolated from vulvovaginal candidiasis. Med. Mycol. 2019, 57, 291-299. [CrossRef]

14. Nelson, M.; Wanjiru, W.; Margaret, M. Identification and susceptibility profile of vaginal Candida species to antifungal agents among pregnant women attending the antenatal clinic of Thika District Hospital, Kenya. Open J. Med. Microbiol. 2013, 3, $239-247$. [CrossRef]

15. Mesquida, A.; Vicente, T.; Reigadas, E.; Palomo, M.; Sánchez-Carrillo, C.; Muñoz, P.; Guinea, J.; Escribano, P. In vitro activity of ibrexafungerp and comparators against Candida albicans genotypes from vaginal samples and blood cultures. Clin. Microbiol. Infect. 2021, 27, e5-e915. [CrossRef] 
16. Rezaei-Matehkolaei, A.; Shafiei, S.; Zarei-Mahmoudabadi, A. Isolation, molecular identification, and antifungal susceptibility profiles of vaginal isolates of Candida species. Iran. J. Microbiol. 2016, 8, 410-417.

17. Kiakojuri, K.; Mahdavi Omran, S.; Roodgari, S.; Taghizadeh Armaki, M.; Hedayati, M.T.; Shokohi, T.; Haghani, I.; Javidnia, J.; Kermani, F.; Badali, H.; et al. Molecular identification and antifungal susceptibility of yeasts and molds isolated from patients with otomycosis. Mycopathologia 2021, 186, 245-257. [CrossRef] [PubMed]

18. Farahyar, S.; Izadi, S.; Razmjou, E.; Falahati, M.; Roudbary, M.; Ashrafi-Khozani, M.; Ansari, S.; Fattahi, A.; Ghahri-Mobaser, Z.; Rahimi, M. Low prevalence of antifungal resistant Candida africana, in the C. albicans complex causing vulvovaginal candidiasis. Heliyon 2020, 6, e03619. [CrossRef]

19. Lotfalikhani, A.; Khosravi, Y.; Sabet, N.S.; Na, S.L.; Ng, K.P.; Tay, S.T. Genetic diversity, antifungal susceptibility and enzymatic characterisation of Malaysian clinical isolates of Candida glabrata. Trop. Biomed. 2018, 35, 1123-1130. [PubMed]

20. Singh, S.; Sobel, J.D.; Bhargava, P.; Boikov, D.; Vazquez, J.A. Vaginitis due to Candida krusei: Epidemiology, clinical aspects, and therapy. Clin. Infect. Dis. 2002, 35, 1066-1070. [CrossRef] [PubMed]

21. Mendling, W.; Atef El Shazly, M.; Zhang, L. Clotrimazole for vulvovaginal candidosis: More than 45 years of clinical experience. Pharmaceuticals 2020, 13, 274. [CrossRef]

22. Marchaim, D.; Lemanek, L.; Bheemreddy, S.; Kaye, K.S.; Sobel, J.D. Fluconazole-resistant Candida albicans vulvovaginitis. Obstet. Gynecol. 2012, 120, 1407-1414. [CrossRef]

23. Khadka, S.; Sherchand, J.B.; Pokhrel, B.M.; Parajuli, K.; Mishra, S.K.; Sharma, S.; Shah, N.; Kattel, H.P.; Dhital, S.; Khatiwada, S.; et al. Isolation, speciation and antifungal susceptibility testing of Candida isolates from various clinical specimens at a tertiary care hospital, Nepal. BMC Res. Notes 2017, 10, 218. [CrossRef] [PubMed]

24. Cross, E.W.; Park, S.; Perlin, D.S. Cross-resistance of clinical isolates of Candida albicans and Candida glabrata to over-the-counter azoles used in the treatment of vaginitis. Microb. Drug Resist. 2000, 6, 155-161. [CrossRef] [PubMed]

25. Makanjuola, O.; Bongomin, F.; Fayemiwo, S.A. An update on the roles of non-albicans Candida species in vulvovaginitis. J. Fungi 2018, 4, 121. [CrossRef] [PubMed]

26. Grimling, B.; Karolewicz, B.; Nawrot, U.; Włodarczyk, K.; Górniak, A. Physicochemical and antifungal properties of clotrimazole in combination with high-molecular weight chitosan as a multifunctional excipient. Mar. Drugs 2020, 18, 591. [CrossRef]

27. Spitzer, M.; Wiederhold, N.P. Reduced antifungal susceptibility of vulvovaginal Candida species at normal vaginal pH levels: Clinical implications. J. Low. Genit. Tract Dis. 2018, 22, 152-158. [CrossRef]

28. Tiboni, M.; Campana, R.; Frangipani, E.; Casettari, L. 3D printed clotrimazole intravaginal ring for the treatment of recurrent vaginal candidiasis. Int. J. Pharm. 2021, 596, 120290. [CrossRef]

29. Catenacci, L.; Marrubini, G.; Sorrenti, M.; Rossi, S.; Sandri, G.; Ferrari, F.; Fagnani, V.; Valentino, C.; Bonferoni, M.C. Design of experiments-assisted development of clotrimazole-loaded ionic polymeric micelles based on hyaluronic acid. Nanomaterials 2020, 10, 635. [CrossRef] [PubMed]

30. Arendrup, M.C.; Meletiadis, J.; Mouton, J.W.; the Subcommittee on Antifungal Susceptibility Testing (AFST) of the ESCMID European Committee for Antimicrobial Susceptibility Testing (EUCAST). Method for the Determination of Broth Dilution Minimum Inhibitory Concentrations of Antifungal Agents for Yeasts. Eucast Definitive Document E.Def. 7.3.1 April 2020. Available online: https:/ / www.eucast.org/ (accessed on 19 October 2020). 